\title{
Prognostic Value of Plasma Renin Activity in Heart Failure
}

\author{
Giuseppe Vergaro, MD ${ }^{\mathrm{a}}$, Michele Emdin, MD, PhD ${ }^{\mathrm{a}}$, Annalisa Iervasi, BSc ${ }^{\mathrm{b}}$, Luc Zyw, BSc ${ }^{\mathrm{a}}$, \\ Alessandra Gabutti, MD ${ }^{\mathrm{a}}$, Roberta Poletti, MD ${ }^{\mathrm{a}}$, Chiara Mammini, MD ${ }^{\mathrm{a}}$, Alberto Giannoni, MD ${ }^{\mathrm{a}}$, \\ Marianna Fontana, $\mathrm{MD}^{\mathrm{a}}$, and Claudio Passino, $\mathrm{MD}^{\mathrm{a}, \mathrm{c}, *}$
}

\begin{abstract}
The prognostic role of specific biomarkers of the renin-angiotensin-aldosterone system and sympathetic activation pathways in heart failure has never been investigated in populations with current evidence-weighted treatment. To establish whether the plasma renin activity (PRA), among several neurohormonal biomarkers, is able to predict cardiac events in a population of patients with heart failure on up-to-date treatment, we selected 996 consecutive patients with systolic left ventricular dysfunction (ejection fraction $<50 \%$, mean age $65 \pm 13$ years), who underwent a complete clinical and humoral characterization and were then followed up (median 36 months, range 0 to 72) for cardiac death and appropriate implantable cardioverter device shock. We recorded 170 cardiac deaths and 27 shocks. On Cox multivariate analysis, only ejection fraction (hazard ratio $0.962,95 \%$ confidence interval 0.938 to 0.986 ), $\mathrm{N}$-terminal pro-brain natriuretic peptide (NT-proBNP; hazard ratio $1.729,95 \%$ confidence interval 1.383 to 2.161 ) and PRA (hazard ratio $1.201,95 \%$ confidence interval 1.024 to 1.408 ) were independent predictors of cardiac death. Receiver operating characteristic curve analysis identified a cutoff value for PRA of $2.30 \mathrm{ng} / \mathrm{ml} / \mathrm{hour}$ that best predicted cardiac mortality. Independent predictors of PRA were ejection fraction, functional class, sodium, potassium, NT-proBNP, norepinephrine, aldosterone, C-reactive protein, and medical therapy. The association of high NT-proBNP and high PRA identified a subgroup ( $22 \%$ of the study population) with the greatest risk of cardiac death. In conclusion, PRA resulted an independent prognostic marker in patients with systolic heart failure additive to NT-proBNP level and ejection fraction. PRA might help to select those patients needing an enhanced therapeutic effort, possibly targeting incomplete reninangiotensin-aldosterone system blockade. (c) 2011 Elsevier Inc. All rights reserved. (Am J Cardiol 2011;108:246-251)
\end{abstract}

The aim of the present study was to establish whether plasma renin activity (PRA) is able to predict cardiac events in patients with heart failure (HF), among a number of clinical and functional parameters and neurohormonal biomarkers in a population of patients with HF receiving upto-date pharmacologic and device treatment.

\section{Methods}

From June 2002 to November 2008, we prospectively enrolled 996 consecutive patients with systolic dysfunction (left ventricular ejection fraction $[\mathrm{EF}]<50 \%$ ), referred to our division for HF management. The diagnosis of HF was determined by the history, symptoms, physical examination, and instrumental findings for the assessment of structural myocardial involvement. Cardiac morphology and function were assessed by 2-dimensional Doppler echocardiography.

Acute coronary syndrome within 6 months before the enrollment was the only exclusion criterion. The characteristics of the sample population are summarized in Table 1 .

\footnotetext{
${ }^{a}$ Division of Cardiovascular Medicine, Fondazione Toscana G. Mon-

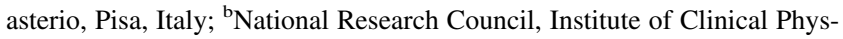
iology, Pisa, Italy; and 'Scuola Superiore Sant'Anna, Pisa, Italy.

*Corresponding author: Tel: (+39) 050-315-2191; fax: (+39) 050315-2109.

E-mail address: passino@ftgm.it (C. Passino).
}

All patients were at the maximum tolerated dose of $\beta$ blockers, angiotensin-converting enzyme inhibitors/angiotensin receptor blockers (ACEIs/ARBs), and aldosterone antagonists and had a controlled dietary sodium daily intake $(<4 \mathrm{~g} \mathrm{NaCl})$. The study protocol was performed according to the Declaration of Helsinki and was approved by the institutional ethics committee, and all subjects provided informed consent.

All patients underwent a comprehensive biohumoral characterization. Blood samples were drawn at 8.00 A.M. after an overnight fast, according to a standardized experimental protocol. ${ }^{1}$ Follow-up started with blood sampling and continued until study termination (i.e., May 2009). Independent interviewers obtained follow-up data directly from the patients, relatives, institute cardiologists, or general practitioners. Information about the time and cause of death was obtained from death certificates, postmortem reports, and family doctors. The primary end point was cardiac death (further distinguished into death from HF progression and sudden death). Appropriate implanted cardioverter defibrillator shocks and sudden death were considered together as a combined end point. Patients who died from noncardiacrelated causes or underwent heart transplantation or ventricular assistance device implantation were considered censored at the event.

Statistical analysis was performed using the Statistical Package for Social Sciences, version 13.0 (SPSS, Chicago, 
Table 1

Characteristics of overall population and subgroups with plasma renin activity (PRA) values $<2.3$ or $>2.3 \mathrm{ng} / \mathrm{ml} / \mathrm{hour}$ cutpoint

\begin{tabular}{|c|c|c|c|c|}
\hline \multirow[t]{2}{*}{ Variable } & \multirow{2}{*}{$\begin{array}{l}\text { All Patients } \\
(\mathrm{n}=996)\end{array}$} & \multicolumn{2}{|c|}{ PRA } & \multirow{2}{*}{$\begin{array}{c}\mathrm{p} \text { Value } \\
\text { (Low vs High) }\end{array}$} \\
\hline & & $\begin{array}{c}\text { Low } \\
(\mathrm{n}=585)\end{array}$ & $\begin{array}{c}\text { High } \\
(\mathrm{n}=411)\end{array}$ & \\
\hline Age (years) & $65 \pm 13$ & $65 \pm 13$ & $65 \pm 12$ & 0.892 \\
\hline Gender & & & & 0.970 \\
\hline Men & $747(75 \%)$ & $438(75 \%)$ & $308(75 \%)$ & \\
\hline Women & $249(25 \%)$ & $147(25 \%)$ & $103(25 \%)$ & \\
\hline Body mass index $\left(\mathrm{kg} / \mathrm{m}^{2}\right)$ & $26.6 \pm 4.8$ & $26.7 \pm 4.6$ & $26.5 \pm 5.1$ & 0.562 \\
\hline Cardiomyopathy etiology & & & & 0.003 \\
\hline Ischemic & $428(43 \%)$ & $228(39 \%)$ & $197(48 \%)$ & \\
\hline Nonischemic & $568(57 \%)$ & $357(61 \%)$ & $214(52 \%)$ & \\
\hline New York Heart Association class & & & & $<0.001$ \\
\hline I-II & $618(62 \%)$ & $404(69 \%)$ & $214(52 \%)$ & \\
\hline III-IV & $378(38 \%)$ & $181(31 \%)$ & $197(48 \%)$ & \\
\hline Atrial fibrillation & $179(18 \%)$ & $94(16 \%)$ & $78(19 \%)$ & 0.630 \\
\hline Ejection fraction (\%) & $32.9 \pm 9.8$ & $34.8 \pm 9.4$ & $30.2 \pm 9.8$ & $<0.001$ \\
\hline End-systolic diameter (mm) & $50 \pm 10$ & $48 \pm 9$ & $52 \pm 11$ & $<0.001$ \\
\hline End-diastolic diameter (mm) & $62 \pm 8$ & $61 \pm 8$ & $63 \pm 9$ & $<0.001$ \\
\hline Left ventricular mass $\left(\mathrm{g} / \mathrm{m}^{2}\right)$ & $146 \pm 37$ & $146 \pm 38$ & $145 \pm 36$ & 0.957 \\
\hline Glomerular filtration rate $(\mathrm{ml} / \mathrm{min})$ & $70.5 \pm 33.9$ & $73.0 \pm 32.6$ & $66.9 \pm 35.6$ & 0.005 \\
\hline Hemoglobin $(\mathrm{g} / \mathrm{dl})$ & $13.5 \pm 1.7$ & $13.60 \pm 1.77$ & $13.44 \pm 1.70$ & 0.166 \\
\hline Free-triiodothyronine $(\mathrm{pg} / \mathrm{ml})$ & $2.4 \pm 0.9$ & $2.44 \pm 1.08$ & $2.37 \pm 0.72$ & 0.287 \\
\hline Free thyroxine $(\mathrm{pg} / \mathrm{ml})$ & $12.90 \pm 5.21$ & $12.27 \pm 4.90$ & $13.79 \pm 5.50$ & $<0.001$ \\
\hline Thyroid stimulating hormone (uUI/ml) & $2.55 \pm 3.84$ & $2.40 \pm 2.75$ & $2.76 \pm 4.99$ & 0.197 \\
\hline $\mathrm{N}$-terminal pro-brain natriuretic peptide (ng/L) & $1,329(467-3,384)$ & $1,116(418-2,939)$ & $1,682(553-4,086)$ & $<0.001$ \\
\hline Epinephrine (ng/L) & $30(13-52)$ & $27(11-48)$ & $33(19-61)$ & $<0.001$ \\
\hline Norepinephrine (ng/L) & $520(342-784)$ & $457(302-659)$ & $602(425-951)$ & $<0.001$ \\
\hline Plasma renin activity (ng/ml/hour) & $1.59(0.43-5.07)$ & $0.56(0.20-1.20)$ & $6.11(3.87-10.72)$ & $<0.001$ \\
\hline Aldosterone $(\mathrm{ng} / \mathrm{L})$ & $145(86-228)$ & $117(72-176)$ & $190(113-319)$ & $<0.001$ \\
\hline \multicolumn{5}{|l|}{ Medications } \\
\hline$\beta$ Blockers & $817(82 \%)$ & $474(81 \%)$ & $341(83 \%)$ & 0.464 \\
\hline $\begin{array}{l}\text { Angiotensin-converting enzyme inhibitors/angiotensin } \\
\text { receptor blockers }\end{array}$ & $827(83 \%)$ & $486(83 \%)$ & $337(82 \%)$ & 0.202 \\
\hline Spironolactone & $598(60 \%)$ & $304(52 \%)$ & $296(72 \%)$ & $<0.001$ \\
\hline Furosemide & $807(81 \%)$ & $439(75 \%)$ & $358(87 \%)$ & $<0.001$ \\
\hline Nitrates & $289(29 \%)$ & $176(30 \%)$ & $111(27 \%)$ & 0.392 \\
\hline Cardiac resynchronization therapy & $90(9 \%)$ & $59(10 \%)$ & $33(8 \%)$ & 0.092 \\
\hline Cardiac resynchronization therapy and defibrillator & $129(13 \%)$ & $53(9 \%)$ & $74(18 \%)$ & $<0.001$ \\
\hline Implanted cardioverter device & $70(7 \%)$ & $41(7 \%)$ & $29(7 \%)$ & 0.909 \\
\hline
\end{tabular}

Data are presented as mean \pm SD for continuous normally distributed variables, median (25th to 75 th percentiles) for continuous non-normally distributed variables, or $\mathrm{n}(\%)$.

Illinois). The data are presented as the mean $\pm \mathrm{SD}$ or as the median and interquartile range for values with a non-normal distribution. Variables with a skewed distribution were logarithmically transformed for parametric analysis. Continuous variables were compared using Student's $t$ test, and discrete variables were compared using the chi-square test. The candidate independent variables used on univariate Cox proportional analysis for prognostic aims were selected by their close association with the HF outcome. In particular, we considered age, gender, body mass index, etiology of cardiomyopathy (ischemic/nonischemic), New York Heart Association class, echocardiographic indexes of left ventricular function (EF), hemoglobin, estimated glomerular filtration rate using Cockroft-Gault's formula, thyroid function (free triiodothyronine), $\gamma$-glutammyl-transferase, neurohormones (N-terminal pro-brain natriuretic peptide [NTproBNP], cortisol, epinephrine, norepinephrine, aldosterone, and PRA), and therapy with diuretics, nitrates, $\beta$ blockers, ACEIs/ARBs, and spironolactone. All the variables found to be significant on univariate analysis were included in the multivariate Cox proportional hazards model. The optimal cutpoints for PRA and NT-proBNP were quantified using receiver operating characteristic curves. The prognostic value of the spectrum of PRA levels was assessed with the P-spline method, ${ }^{2}$ fitting data to a set of spline basis functions with a reduced set of knots, combined with the roughness penalty of smoothing splines. The Kaplan-Meier life table, estimating cardiac-related death, was used to summarize the follow-up experience in the patient population. Differences in survival curves were tested with the log-rank test (Mantel-Cox). The same variables used for the survival analysis were entered into the univariate linear regression analysis to examine the association with PRA, together with the serum glucose, sodium, potassium, thyroid-stimulating hormone, and C-reactive protein. The significant univariate predictors were then en- 
Table 2

Univariate and multivariate analysis of predictors for cardiac mortality

\begin{tabular}{|c|c|c|c|c|}
\hline \multirow[t]{2}{*}{ Variable } & \multicolumn{2}{|c|}{ Univariate Model } & \multicolumn{2}{|c|}{ Multivariate Model } \\
\hline & Hazard Ratio $(95 \%$ CI) & $\mathrm{p}$ Value & Hazard Ratio (95\% CI) & $\mathrm{p}$ Value \\
\hline Age & $1.257(1.146-1.379)$ & $<0.001$ & - & - \\
\hline Body mass index & $0.826(0.751-0.908)$ & $<0.001$ & - & - \\
\hline New York Heart Association class & $3.855(2.775-5.356)$ & $<0.001$ & - & - \\
\hline Ejection fraction & $0.693(0.634-0.758)$ & $<0.001$ & $0.962(0.938-0.986)$ & 0.002 \\
\hline Etiology (ischemic) & $1.746(1.278-2.387)$ & $<0.001$ & - & - \\
\hline Free triiodothyronine & $0.755(0.671-0.895)$ & 0.001 & - & - \\
\hline Hemoglobin & $0.803(0.740-0.871)$ & $<0.001$ & - & - \\
\hline Glomerular filtration rate & $0.647(0.579-0.724)$ & $<0.001$ & - & - \\
\hline Cortisol & $1.193(1.134-1.255)$ & $<0.001$ & - & - \\
\hline$\gamma$-Glutamyltransferase & $1.155(1.073-1.243)$ & $<0.001$ & - & - \\
\hline $\mathrm{N}$-terminal pro-brain natriuretic peptide & $1.860(1.682-2.057)$ & $<0.001$ & $1.729(1.383-2.161)$ & $<0.001$ \\
\hline Plasma renin activity & $1.293(1.194-1.401)$ & $<0.001$ & $1.201(1.024-1.408)$ & 0.024 \\
\hline Epinephrine & $1.227(1.136-1.325)$ & $<0.001$ & - & - \\
\hline Norepinephrine & $1.308(1.205-1.419)$ & $<0.001$ & - & - \\
\hline Aldosterone & $1.127(1.038-1.223)$ & 0.004 & - & - \\
\hline $\begin{array}{l}\text { Angiotensin-converting enzyme inhibitors/angiotensin } \\
\text { receptor blockers }\end{array}$ & $0.532(0.371-0.763)$ & 0.001 & - & - \\
\hline Spironolactone & $1.761(1.249-2.483)$ & 0.001 & - & - \\
\hline Nitrates & $1.699(1.223-2.361)$ & 0.002 & - & - \\
\hline Furosemide & $2.352(1.380-4.008)$ & 0.002 & - & - \\
\hline
\end{tabular}

Data are presented as median (range).

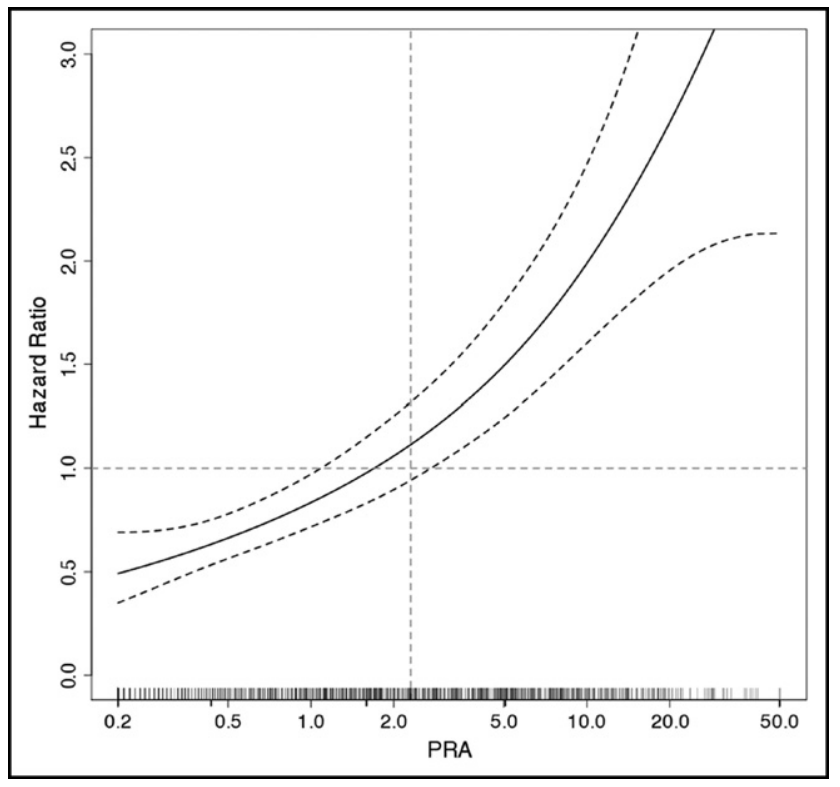

Figure 1. PRA P-spline hazard ratio plot for cardiac mortality. Curve shows exponential behavior with risk increasing for greater PRA. Vertical line indicates PRA value corresponding to $2.3 \mathrm{ng} / \mathrm{ml} /$ hour cutpoint.

tered into the multivariate linear regression analysis. A p value $<0.05$ was considered significant.

\section{Results}

During a median follow-up of 36 months (range 0 to 72 ), 290 deaths occurred. Of the 290 patients who died, 170 died from cardiac causes (124 from associated HF progression, 26 from sudden death, 15 from acute myocardial infarction, and 5 perioperative), and 27 implanted cardioverter defibrillator shocks were observed. Five patients underwent heart transplantation and one ventricular assist device implantation, as destination therapy.

On Cox univariate analysis age, body mass index, New York Heart Association class, EF, etiology of cardiomyopathy, free triiodothyronine, hemoglobin, estimated glomerular filtration rate, cortisol, $\gamma$-glutammyl-transferase, NTproBNP, PRA, epinephrine, norepinephrine, aldosterone, and therapy with ACEIs/ARBs, spironolactone, nitrates, or diuretics were predictors of cardiac death. On multivariate analysis, only EF, NT-proBNP, and PRA were independent predictors of cardiac death (Table 2).

On receiver operating characteristic analysis, the cutoff value of $2.30 \mathrm{ng} / \mathrm{ml} / \mathrm{hour}$ for PRA best predicted cardiac mortality (area under the receiver operating characteristic curve 0.649 ; sensitivity $59 \%$, specificity $62 \%$ ). An increased risk of cardiac mortality in terms of the hazard ratio (hazard ratio $>1$ ) at P-spline analysis (Figure 1) was observed for PRA levels of $>1.8 \mathrm{ng} / \mathrm{ml} /$ hour.

As listed in Table 1, patients with PRA levels $>2.30$ $\mathrm{ng} / \mathrm{ml} /$ hour had a greater New York Heart Association functional class, presented more frequently with ischemic dysfunction, had worse left ventricular EF and greater left ventricular diameters, lower estimated glomerular filtration rate, and greater plasma NT-proBNP, epinephrine, norepinephrine, and aldosterone levels. Patients with greater PRA were also more frequently treated with spironolactone and furosemide and device therapy.

As shown in the Kaplan-Meier analysis, patients with PRA $>2.30 \mathrm{ng} / \mathrm{ml} /$ hour had a much greater rate of cardiac death, death from HF progression, and the composite end point of sudden death plus implanted cardioverter defibrillator shock (Figure 2). The use of drugs exerting reninangiotensin-aldosterone system antagonism did not alter the prognostic value of PRA. 


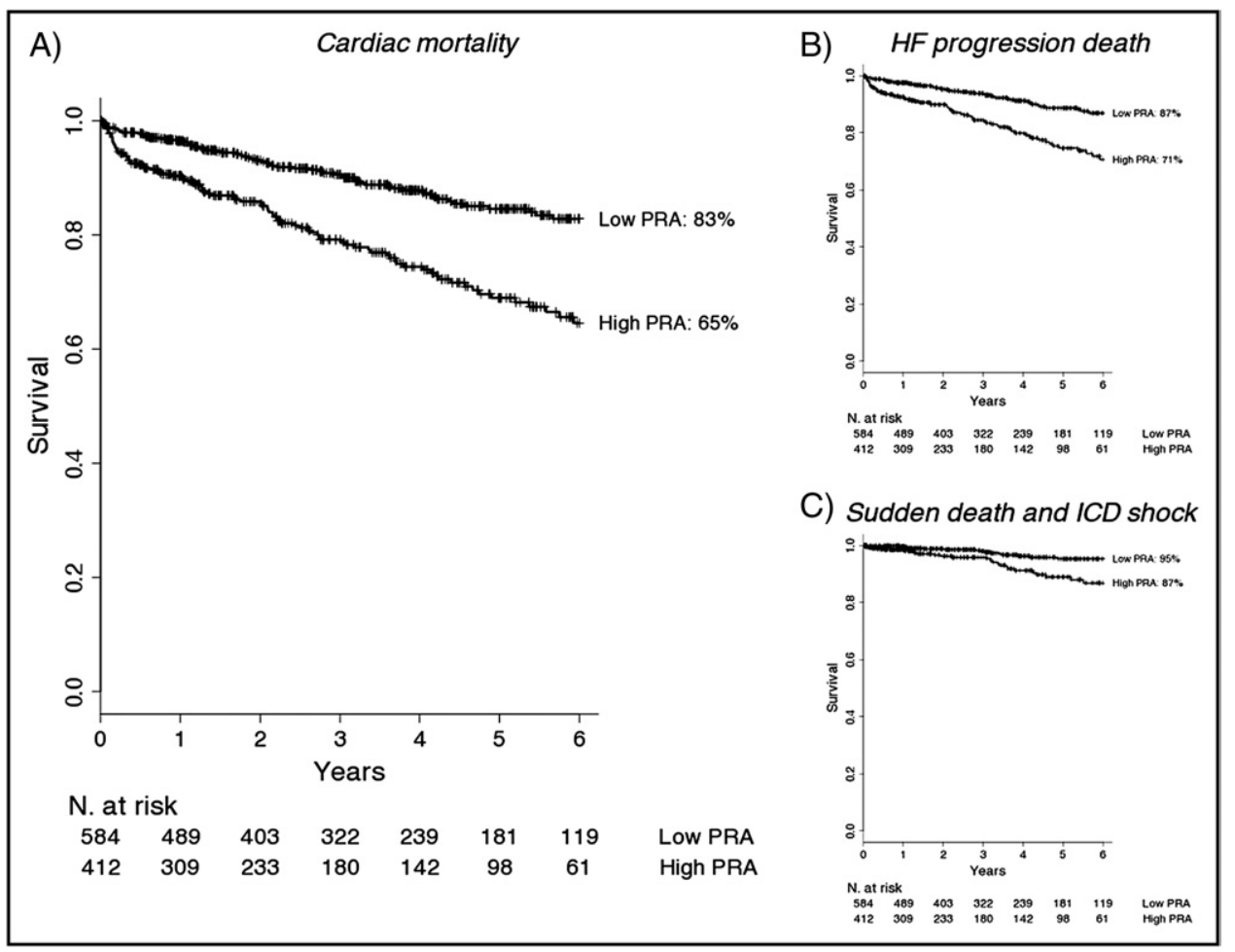

Figure 2. Kaplan-Meier survival analysis for cardiac mortality $(A)$, death from HF progression $(B)$, and composite end point of sudden death plus implanted cardioverter defibrillator shock $(C)$ in patients according to $2.3-\mathrm{ng} / \mathrm{ml} /$ hour cutpoint. High PRA $=2.3 \mathrm{ng} / \mathrm{ml} /$ hour; low PRA $=<2.3 \mathrm{ng} / \mathrm{ml} / \mathrm{hour}$.

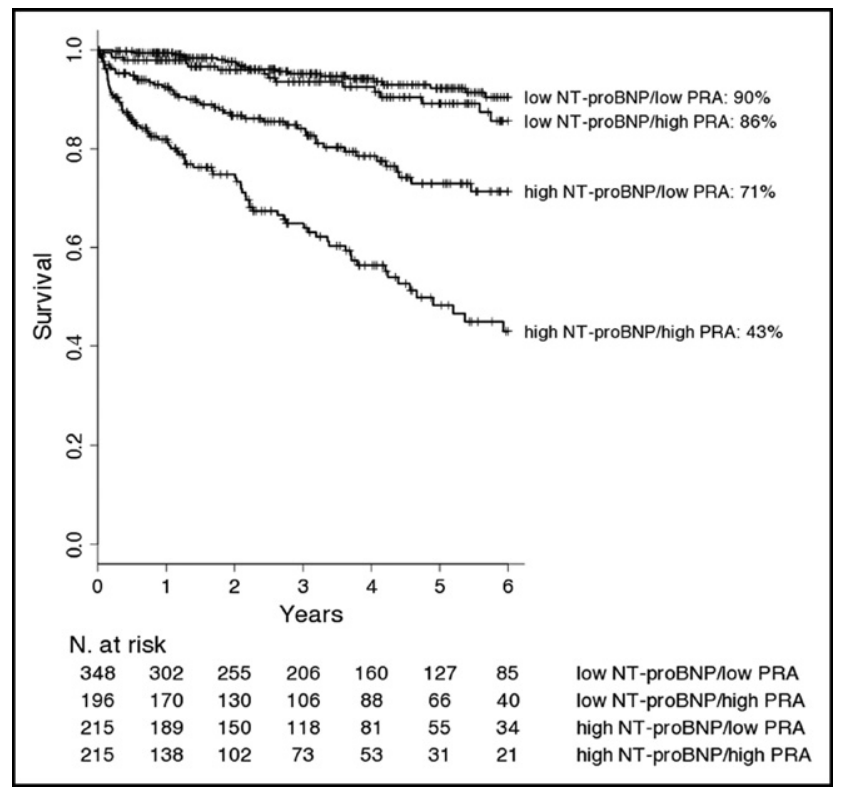

Figure 3. Kaplan-Meier survival curves for cardiac death in 4 subsets identified according to cutpoint values of $2.3 \mathrm{ng} / \mathrm{ml} / \mathrm{hour}$ for PRA and 1,581 ng/L for NT-proBNP; $\mathrm{p}=\mathrm{NS}$ for low NT-proBNP/low PRA versus low NT-proBNP/high PRA; $p<0.001$ for all other comparisons.

On receiver operating characteristic analysis, the optimal cutpoint for plasma NT-proBNP was 1,581 ng/L (area under the curve 0.765 , sensitivity $66 \%$, specificity $60 \%$ ) for cardiac mortality. As shown in Figure 3, the association of high
NT-proBNP and high PRA identified a subgroup of 215 patients (22\% of the study population) with the greatest risk of cardiac death.

On univariate analysis, an increased PRA level was associated with EF, New York Heart Association functional class, cardiomyopathy etiology, estimated glomerular filtration rate, glucose, plasma sodium and potassium, cortisol, NT-proBNP, epinephrine, norepinephrine, aldosterone, $\gamma$-glutammyl-transferase, C-reactive protein, and therapy with ACEIs/ARBs, spironolactone, and furosemide. On multivariate analysis, only $\mathrm{EF}(R=0.26, \mathrm{p}=0.001)$, New York Heart Association class $(R=0.20, \mathrm{p}=0.006)$, sodium $(R=0.41, \mathrm{p}<0.001)$, potassium $(R=0.09, \mathrm{p}=$ $0.018)$, NT-proBNP $(R=0.11, \mathrm{p}<0.001)$, norepinephrine $(R=0.34, \mathrm{p}<0.001)$, aldosterone $(R=0.39, \mathrm{p}<0.001)$, C-reactive protein $(R=0.13, \mathrm{p}=0.042)$, and therapy with spironolactone $(R=0.29, \mathrm{p}=0.002)$ and ACEIs/ARBs $(R=0.08, \mathrm{p}=0.002)$ were independent predictors of high PRA $\left(R^{2}=0.62\right.$ for the total model $)$.

\section{Discussion}

In the present prospective series of patients with systolic HF, PRA and NT-proBNP, together with EF, showed an independent, additive, predictive value for cardiac death, among a comprehensive panel of neurohormonal and clinical biomarkers. Several variables independently predicted PRA, suggesting the involvement of diverse mechanisms accounting for its prognostic power.

Since the neurohormonal hypothesis, ${ }^{3}$ the search for basic pathophysiologic mechanisms of HF progression has shifted from hemodynamics to peripheral feedback systems 
and to neuroendocrine factors. Pioneering work by Cohn et al and others has highlighted the prognostic relevance of the plasma norepinephrine level and renin activity ${ }^{4-10}$; thus, neurohormonal antagonism with $\beta$ blockers, ACEIs, ARBs, and spironolactone has become a cornerstone of treatment ${ }^{11}$ together with electrical therapy ${ }^{12}$ and aerobic training, ${ }^{13}$ all able to blunt neurohormonal activation in HF.

B-type natriuretic peptides are currently considered the best prognosticators in $\mathrm{HF}$ among neuroendocrine biomarkers. ${ }^{14}$ Nonetheless, as markers of ventricular overload and myocyte stress, they are also nonspecific ${ }^{15}$; thus, biomarkers more directly linked to causal pathways would be desired for multimarker prognostic stratification strategy of patients with HF.

Renin-angiotensin system activation, as assessed by PRA, holds a pivotal pathophysiologic meaning in HF, as indicated by several effects on ventricular remodeling, hemodynamics, and renal function, through angiotensin II and aldosterone production. ${ }^{16-20}$ Although biomarkers of several neurohormonal axes examined (i.e., sympathetic nervous system, thyroid, adrenal gland) were univariate predictors in our analysis, PRA independently predicted the occurrence of cardiac death in the systolic HF population and identified, among patients with a high NT-proBNP level, a consistent subgroup (22\% of the whole population) with a markedly increased risk of cardiac death.

In the present study, PRA was assayed in patients mostly treated with $\beta$ blockers, diuretics, ACEIs/ARBs, and aldosterone antagonists, all known to influence PRA. Our results have shown that PRA elevation, owing to the intrinsic mechanisms of disease progression and/or a rebound increase secondary to ACEIs, ARBs, or spironolactone therapy might significantly affect the disease evolution and clinical outcome, either directly (through renin effects on prorenin/renin receptors) or indirectly (through the stimulation of angiotensin II and aldosterone synthesis), depicting, as for ACE or aldosterone, the frame of a "PRA escape."

A combined assay of PRA and NT-proBNP might identify a significant proportion of patients with HF with incomplete neuroendocrine antagonism using current pharmacologic treatment, who would potentially benefit by additional, enhanced, or differential therapeutic strategies for renin-angiotensin-aldosterone system antagonism. This seems even more worthwhile given the current/future availability of new drugs acting on the renin-angiotensinaldosterone system cascade, such as direct renin inhibitors, ${ }^{21,22}$ known to reduce PRA (but whose effect on patient outcome is still unknown), or aldosterone synthase inhibitors, still under experimental investigation. ${ }^{23}$ PRA might be valuable as either a prognostic marker or a potential therapeutic target.

Our findings have confirmed and extended the results from previous studies by Latini et $\mathrm{al}^{7}$ and Masson et $\mathrm{al}^{24}$ in a subset of patients with HF from the Valsartan Heart Failure Trial (Val-HeFT) study. However, the patients enrolled in these studies were undertreated in terms of the use of $\beta$ blockers and spironolactone compared to current indications. In particular, the relatively low rate $(36 \%)$ of $\beta$-blocker therapy (blunting the adrenergic stimulatory effect on renin release $)^{25,26}$ might explain the greater median
PRA level observed in both studies (5.26, interquartile range 1.62 to $16.36 \mathrm{ng} / \mathrm{ml} /$ hour).

Given the value of PRA in predicting cardiac mortality and its key role in assessing the degree of renin-angiotensinaldosterone system activation, a main pathway in HF progression, we investigated which clinical and neurohormonal variables influenced its level more. Our results identified EF, New York Heart Association class, sodium, potassium, NT-proBNP, norepinephrine, aldosterone, C-reactive protein, and therapy with ACEIs/ARBs and spironolactone as predictors of PRA, suggesting that it is affected by both cardiac and systemic factors and influenced by renin-angiotensin-aldosterone system antagonist drugs. ${ }^{27} \mathrm{In}$ particular, the close relation found between PRA and aldosterone level can be explained by a feedback mechanism, associated with the stimulatory effect of aldosterone on renin and ACE gene expression, ${ }^{28,29}$ as well as by a feed-forward mechanism, through the aldosterone escape phenomenon (i.e., aldosterone synthesis stimulation by alternative biochemical paths, such as chymases), in patients receiving ACEIs/ ARBs therapy. ${ }^{30}$

As a possible limitation, preanalytical and analytic issues are known to affect catecholamine and plasma renin assay, although a rigorous, standardized protocol of blood sampling and sample assay minimized every potential interference in our setting.

In conclusion, our results have indicated that PRA has an independent prognostic value in patients with systolic HF, irrespective of medical treatment, additive to NT-proBNP level and EF and could thus be used along side other currently available biohumoral markers in the multimarker strategy of HF prognostic stratification. Furthermore, PRA, playing a central role in renin-angiotensin-aldosterone system feedback regulation, as well as in the development of pathophysiologic and clinical features of HF syndrome, might help in selecting those patients needing an enhanced therapeutic effort, possibly targeting incomplete renin-angiotensin-aldosterone system blockade. The prognostic role of PRA should be confirmed in larger populations and in different settings (e.g., diastolic HF). Finally, it would be of interest to investigate the effects of drugs directly affecting renin enzymatic activity (e.g., direct renin inhibitors) on both PRA and prognosis in patients with HF.

1. Emdin M, Passino C, Prontera C, Iervasi A, Ripoli A, Masini S, Zucchelli GC, Clerico A. Cardiac natriuretic hormones, neuro-hormones, thyroid hormones and cytokines in normal subjects and patients with heart failure. Clin Chem Lab Med 2004;42:627-636.

2. Hellers PHC, Marx BD. Flexible smoothing with B-spline and penalties. Stat Sci 1996;11:89-102.

3. Packer M. The neurohormonal hypothesis: a theory to explain the mechanism of disease progression in heart failure. J Am Coll Cardiol 1992;20:248-254.

4. Francis GS, Cohn JN, Johnson G, Rector TS, Goldman S, Simon A; V-HeFT VA Cooperative Studies Group. Plasma norepinephrine, plasma renin activity, and congestive heart failure: relations to survival and the effects of therapy in V-HeFT II. Circulation 1993;87:VI40VI48.

5. Benedict CR, Johnston DE, Weiner DH, Bourassa MG, Bittner V, Kay R, Kirlin P, Greenberg B, Kohn RM, Nicklas JM; SOLVD Investigators. Relation of neurohormonal activation to clinical variables and degree of ventricular dysfunction: a report from the Registry of Studies of Left Ventricular Dysfunction. J Am Coll Cardiol 1994;23:14101420. 
6. Benedict CR, Shelton B, Johnstone de Francis G, Greenberg B, Konstam M, Probstfield JL, Yusuf S. Prognostic significance of plasma norepinephrine in patients with asymptomatic left ventricular dysfunction. Circulation 1996;94:690-697.

7. Latini R, Masson S, Anand I, Salio M, Hester A, Judd D, Barlera S, Maggioni AP, Tognoni G, Cohn JN; Val-HeFT Investigators. The comparative prognostic value of plasma neurohormones at baseline in patients with heart failure enrolled in Val-HeFT. Eur Heart J 2004; 25:292-299.

8. Yan RT, White M, Yan AT, Yusuf S, Rouleau JL, Maggioni AP, Hall C, Latini R, Afzal R, Floras J, Masson S, McKelvie RS; Randomized Evaluation of Strategies for Left Ventricular Dysfunction (RESOLVD) Investigators. Usefulness of temporal changes in neurohormones as a marker of ventricular remodeling and prognosis in patients with left ventricular systolic dysfunction and heart failure receiving either candesartan or enalapril or both. Am J Cardiol 2005;96:698-704.

9. Sigurdsson A, Eriksson SV, Hall C, Kahan T, Swedberg K. Early neurohormonal effects of trandolapril in patients with left ventricular dysfunction and a recent acute myocardial infarction: a double-blind, randomized, placebo-controlled multicentre study. Eur J Heart Fail 2001;3:69-78.

10. Cohn JN, Levine TB, Olivari MT, Garberg V, Lura D, Francis GS, Simon AB, Rector T. Plasma norepinephrine as a guide to prognosis in patients with chronic congestive heart failure. N Engl J Med 1984; 311:819-823.

11. Hamad E, Mather PJ, Srinivasan S, Rubin S, Whellan DJ, Feldman AM. Pharmacological therapy of chronic heart failure. Am J Cardiovasc Drugs 2007;7:235-248.

12. Burkhardt JD, Wilkoff BL. Interventional electrophysiology and cardiac resynchronization therapy: delivering electrical therapies for heart failure. Circulation 2007;115:2208-2220.

13. Passino C, Severino S, Poletti R, Piepoli MF, Mammini C, Clerico A, Gabutti A, Nassi G, Emdin M. Aerobic training decreases B-type natriuretic peptide expression and adrenergic activation in patients with heart failure. J Am Coll Cardiol 2006;47:1835-1839.

14. Emdin M, Vittorini S, Passino C, Clerico A. Old and new biomarkers of heart failure. Eur J Heart Fail 2009;11:331-335.

15. Braunwald E. Biomarkers in heart failure. N Engl J Med 2008;358: $2148-2159$.

16. Saris JJ, t'Hoen PA, Garrelds IM, Dekkers DH, den Dunnen JT, Lamers JM, Jan Danser AH. Prorenin induces intracellular signaling in cardiomyocytes independently of angiotensin II. Hypertension 2006;48:564-571.

17. Nguyen G. Renin/prorenin receptors. Kidney Int 2006;69:1503-1506.

18. Min LJ, Mogi M, Li JM, Iwanami J, Iwai M, Horiuchi M. Aldosterone and angiotensin II synergistically induce mitogenic response in vascular smooth muscle cells. Circ Res 2005;97:434-442.
19. Karram T, Abbasi A, Keidar S, Golomb E, Hochberg I, Winaver J, Hoffman A, Abassi Z. Effects of spironolactone and eprosartan on cardiac remodeling and angiotensin-converting enzyme isoforms in rats with experimental heart failure. Am J Physiol Heart Circ Physiol 2005;289:H1351-H1358.

20. Chan AK, Sanderson JE, Wang T, Lam W, Yip G, Wang M, Lam YY, Zhang Y, Yeung L, Wu EB, Chan WW, Wong JT, So N, Yu CM. Aldosterone receptor antagonism induces reverse remodeling when added to angiotensin receptor blockade in chronic heart failure. $J \mathrm{Am}$ Coll Cardiol 2007;50:591-596.

21. McMurray JJ, Pitt B, Latini R, Maggioni AP, Solomon SD, Keefe DL, Ford J, Verma A, Lewsey J; Aliskiren Observation of Heart Failure Treatment (ALOFT) Investigators. Effects of the oral direct renin inhibitor aliskiren in patients with symptomatic heart failure. Circ Heart Fail 2008;1:17-24.

22. Brown MJ. Aliskiren. Circulation 2008;118:773-784.

23. Mulder P, Mellin V, Favre J, Vercauteren M, Remy-Jouet I, Monteil C, Richard V, Renet S, Henry JP, Jeng AY, Webb RL, Thuillez C. Aldosterone synthase inhibition improves cardiovascular function and structure in rats with heart failure: a comparison with spironolactone. Eur Heart $J$ 2008;29:2171-2179.

24. Masson S, Solomon S, Angelici L, Latini R, Anand IS, Prescott M, Maggioni AP, Tognoni G, Cohn JN; Val-Heft Investigators. Elevated plasma renin activity predicts adverse outcome in chronic heart failure, independently of pharmacologic therapy: data from the Valsartan Heart Failure Trial (Val-HeFT). J Card Fail 2010;16:964-970.

25. Hsueh WA, Goldstone R, Carlson EJ, Horton R. Evidence that the beta-adrenergic system and prostaglandins stimulate renin release through different mechanisms. J Clin Endocrinol Metab 1985;61:399403.

26. Licht MR, Izzo JL Jr. Humoral effect of norepinephrine on renin release in humans. Am J Hypertens 1989;2:788-791.

27. Ichihara A, Kobori H, Miyashita Y, Hayashi M, Saruta T. Differential effects of thyroid hormone on renin secretion, content, and mRNA in juxtaglomerular cells. Am J Physiol 1998;274:E224-E231.

28. Klar J, Vitzthum H, Kurtz A. Aldosterone enhances renin gene expression in juxtaglomerular cells. Am J Physiol Ren Physiol 2004;286: F349-F355.

29. Sugiyama T, Yoshimoto T, Tsuchiya K, Gochou N, Hirono Y, Tateno T, Fukai N, Shichiri M, Hirata Y. Aldosterone induces angiotensin converting enzyme gene expression via a JAK2-dependent pathway in rat endothelial cells. Endocrinology 2005;146:3900-3906.

30. Struthers AD. The clinical implications of aldosterone escape in congestive heart failure. Eur J Heart Fail 2004;6:539-545. 